\title{
Analisis terhadap Kemampuan Doing Mathematics Mahasiswa pada Perkuliahan Kapita Selekta Matematika Sekolah
}

\author{
A.S. Hidayat ${ }^{1}$, E. Cahya, dan Wahyudin \\ Dosen Jurusan Pendidikan Matematika FPMIPPA UPI Bandung \\ Email: hasyhi@yahoo.com ${ }^{1}$
}

\begin{abstract}
Abstrak
Salah satu indikator keberhasilan Sekolah Matematika belajar adalah realisasi maksimal matematika kompetensi melakukan melibatkan pemecahan masalah, penalaran, komunikasi, koneksi, representasi, dan pemahaman konseptual, diwujudkan dalam kebiasaan berpikir dan melakukan. Penelitian ini merupakan penelitian deskriptif dengan pendekatan survei dimaksudkan untuk mengetahui pengaruh Sekolah Matematika digest belajar untuk melakukan matematika kompetensi siswa, dan perbaikannya. Para siswa yang dipilih sebagai subjek penelitian adalah mereka yang mengambil Sekolah Matematika Digest 1 saja, di semester genap dari 2013-2014. Hasil penelitian menunjukkan bahwa Sekolah Matematika Digest 1 tentu saja memiliki pengaruh yang kuat pada peningkatan kompetensi melakukan matematika siswa, baik komponen dengan komponen dan sepenuhnya, yaitu, kompetensi penalaran, komunikasi, koneksi, representasi, pemahaman konseptual, dan membuktikan. Selain itu, ditemukan bahwa $86 \%$ siswa dari matematika pemecahan masalah kompetensi yang sangat baik, sisanya $14 \%$ berada pada tingkat cukup. Sementara itu, kualitas peningkatan kompetensi melakukan matematika siswa, baik komponen dengan komponen dan sepenuhnya, jatuh ke dalam kategori yang adil.
\end{abstract}

Kata Kunci: Doing Mathematics, Kapita Selekta Matematika Sekolah

\begin{abstract}
One of the indicators of the success of School Mathematics learning is the maximal realization of the doing mathematics competences involving problem solving, reasoning, communication, connection, representation, and conceptual comprehension, realized in the habits of thinking and doing. The research was a descriptive research by a survey approach intended to determine the influence of School Mathematics digest learning on students'doing mathematics competence, and its improvement. The students selected as the subjects of research were those who took School Mathematics Digest 1 course, in the even semester of 2013-2014. The research findings showed that School Mathematics Digest 1 course has a strong influence on the improvement of the students' doing mathematics competence, both component by component and wholly, i.e., reasoning competence, communication, connection, representation, conceptual comprehension, and proving. In addition, it was found that $86 \%$ students were of very good mathematic problem solving competence, the remaining $14 \%$ being at an insufficient level. Meanwhile, the quality of the improvement of students'doing mathematics competence, both component by component and wholly, fell into a category of fair.
\end{abstract}

Keywords: Doing Mathematics, Capita Selecta School Mathematics

\section{Informasi Tentang Artikel}

$\begin{array}{ll}\text { Diterima pada } & : \text { 20 Oktober } 2014 \\ \text { Disetujui pada } & : 21 \text { November } 2014 \\ \text { Diterbitkan } & : \text { Desember } 2014\end{array}$




\section{PENDAHULUAN}

Periode 1960-an, siswa dan guru di Amerika Serikat mengalami gerakan reformasi matematika yang disebut sebagai the New Math, atau Matematika Baru, yang dipicu peluncuran satelit-satelit Sputnik oleh Uni Soviet pada tahun 1957 dan 1958. Keberhasilan program Sputnik menimbulkan ketakutan nasional akan ketertinggalan dari negara-negara lain di dunia dan mendorong para pendidik di Amerika Serikat untuk mempertimbangkan kembali topik-topik yang digali dalam kurikulum. Di dalam bukunya $A$ Parent's Guide to the New Mathematics (1964), Evelyn Sharp membahas perlunya kurikulum matematika disesuaikan dengan zaman, dengan mengangkat bahwa guru dari abad ketujuh belas dapat siap tampil di kelas 1960-an dan mengajarkan matematika karena "muatan mata pelajaran-mata pelajaran matematika tidak berubah selama 300 tahun."

Menyadari perlunya kesanggupan para matematikawan dan ilmuwan untuk berkompetisi di tingkat global, Matematika Baru memperkenalkan topik-topik seperti teori himpunan dan geometri non-Euclid kepada siswa-siswa sekolah menengah, yang secara historis tidak dikaji sebelum jenjang perguruan tinggi. Sharp melihat Matematika Baru memindahkan topik-topik matematika ke tingkat-tingkat kelas lebih rendah untuk memastikan "semua siswa" mempelajari muatan yang menuntut keketatan jauh lebih tinggi daripada sebelumnya. Di dalam bukunya yang terkenal, Why Johnny Can't Add (1973, 21-2), Morris Kline menyerang Matematika Baru dengan gagasan sebagai berikut: Matematika yang baru diajarkan kepada para siswa sekolah dasar dan sekolah menengah yang pada akhirnya akan memasuki beraneka profesi, bisnis, pekerjaan teknis, dan perdagangan atau menjadi terutama para istri dan ibu rumah tangga. Di antara para siswa sekolah dasar, tidaklah satu dari seribu akan menjadi matematikawan; dan di antara para siswa sekolah menengah, tidaklah satu dari seratus yang akan menjadi matematikawan. Dengan demikian jelas bahwa suatu kurikulum yang barangkali ideal untuk pelatihan matematikawan akanlah masih tidak tepat untuk jenjang-jenjang pendidikan tersebut. Di dalam upaya untuk mengedepankan semua siswa kepada matematika tingkat tinggi, gerakan Matematika Baru dipandang lebih melayani siswa-siswa terbaik dibandingkan para siswa matematika yang marginal atau rata-rata. Selain itu, masyarakat terbingungkan dengan maksudnya, dan gerakan itu pada akhirnya tersisihkan, digantikan oleh gerakan "back to basics" pada periode 1970-an.

Namun demikian, upaya reformasi matematika yang dimulai pada periode 1980-an sangat berbeda. Pada tahun 1980, the National Council of Teachers of Mathematics menyerang "back to basics" dalam buku yang terkenal An Agenda for Action (1980) dengan mengemukakan bahwa pemecahan masalah seharusnya menjadi fokus dari kurikulum. The NCTM kemudian mengeluarkan serangkaian tiga dokumen Standar pada tahun 1989 (Curriculum and Evaluation Standards for School Mathematics), 1991 (Professional Standards for Teaching Mathematics), dan 1995 (Assessment Standards for School Mathematics). Isi dari dokumen-dokumen itu kemudian disesuaikan dan diperbaiki menjadi satu volume Principles and Standards for School Mathematics, untuk menetapkan sifat umum pendidikan matematika millenium ketiga. Suatu standar adalah tolak ukur atau patokan yang dapat digunakan oleh suatu sekolah, kota, propinsi, atau negara untuk menentukan tingkatan sejauh mana program pendidikan memenuhi serangkaian anjuran-anjuran. Dokumen-dokumen Standar yang dikeluarkan oleh NCTM menekankan bahwa matematika seharusnya untuk semua siswa-tanpa memperbedakan jenis kelamin, ras, status sosio-ekonomi, atau faktor lain apa pun yang mungkin telah menyebabkan ketidakadilan di masa silam. Cara berpikir ini merupakan suatu undangan bagi siswa-siswa yang lebih kuat maupun yang lebih lemah untuk membangun kemampuan-kemampuan matematis mereka dan juga merupakan tantangan bagi para guru untuk melihat bagaimana hendaknya menjadikan pembelajaran matematika aksesibel bagi semua siswa. 
Saat kita berpikiran bahwa matematika untuk semua siswa, maka kita akan perlu memperhatikan penelitian tentang praktek-praktek pembelajaran matematika yang efektif. Di dalam kumpulan penelitian itu terdapat banyak sekali evidensi tentang bagaimana mengatur kelas, bagaimana mengangkat masalah-masalah yang bermakna dan memotivasi, serta bagaimana menggunakan teknologi dan strategi-strategi pembelajaran seperti belajar kooperatif untuk mewadahi gaya belajar dan tingkat kepercayaan diri para siswa yang sangat beragam di ruang kelas. Sekarang kita asumsikan, sebagai premis, bahwa semua siswa di ruang kelas-ruang kelas sekolah menengah sanggup mempelajari matematika, dan kita dapat mulai memutuskan bagaimana mengatur pengalaman-pengalaman belajar untuk para siswa yang akan menarik keingintahuan dan daya berpikir mereka sekaligus. Jika para siswa dapat secara aktif ikut serta dalam "melakukan" matematika, maka mereka barangkali akan cukup termotivasi untuk menampilkan yang terbaik di ruang kelas dan dalam tugas-tugas mereka.

Agar siswa memiliki kemampuan doing mathematics yang baik maka diperlukan para pengajar (guru matematika) yang memiliki kemampuan doing mathematics yang tinggi pula. Guru matematika yang memiliki kemapuan doing mathematics yang tinggi niscaya harus seorang guru yang ketika menimba ilmu di perguruan tingginya diberi pengalaman tentang bagaimana agar mahasiswa calon guru tersebut memiliki kemampuan doing mathematics. Salah satu matakuliah yang sangat stategis dalam memberikan pengalaman berdoing mathematics bagi para mahasiswanya adalah matakuliah Kapita Selekta Matematika Sekolah.

Bedasarkan uraian diatas, maka perlu diadakan penelitian yang menyangkut permasalahan kemampuan doing mathematics para mahasiswa calon guru matematika pada perkuliahan Kapita Selekta Matematika Sekolah.

Permasalahan umum di dalam penelitian ini adalah bagaimana kemampu- an doing mathematics para mahasiswa calon guru matematika pada perkuliahan Kapita Selekta Matematika. Secara khusus permasalahan tersebut adalah bagaimanakah gambaran kemampuan doing mathematics para mahasiswa yang menyangkut kemampuan-kemampuan pemecahan masalah (problem solving), penalaran (reasoning), komunikasi (communication), koneksi (connection), representasi (representation), dan pemahaman konseptual (conceptual understanding).

Penelitian ini bertujuan untuk memperoleh gambaran tentang kemampuan-kemampuan pemecahan masalah, penalaran, komunikasi, koneksi, representasi, dan pemahaman konseptual para mahasiswa jurusan pendidikan matematika pada perkuliahan Kapita Selekta

Selanjutnya, penelitian ini diharapkan dapat bermanfaat bagi pengajar matakuliah Kapita Selekta atau matakuliah lainnya, dan para peneliti lainnya, untuk dijadikan pertimbangan-pertimbangan dalam perkuliahan untuk para mahasiswa jurusan pendidikan matematika.

\section{METODOLOGI}

Sesuai dengan permasalahan dan tujuan penelitian, maka penelitian ini adalah penelitian deskriptif yang menggunakan pendekatan survey. Pendekatan survey yang digunakan dalam penelitian ini bermaksud hanya untuk menganalisis kecenderungan-kecenderungan para mahasiswa sekaitan dengan pencapaiannya dalam kemampuan pemecahan masalah, penalaran, komunikasi, koneksi, representasi, pemahaman konseptual, dan pembuktian pada perkuliahan Kapita Selekta Matematika Sekolah.

Subjek dalam penelitian ini adalah semua mahasiswa yang mengikuti perkuliahan Kapita Selekta Matematika Sekolah 1, dan instrumen yang digunakan untuk pengumpulan data adalah seperangkat tes tentang kemampuan pemecahan masalah, penalaran, komunikasi, koneksi, representasi, pembuktian dan pemahaman konseptual pada perkuliahan Kapita Selekta Matematika Sekolah. 
A.S. Hidayat, E. Cahya, dan Wahyudin

Analisis terhadap Kemampuan Doing Mathematics Mahasiswa pada Perkuliahan Kapita Selekta ...

Tabel 1. Rekapitulasi nilai Effect Sizes dan N Gain

Kemampuan doing mathematics

\begin{tabular}{lcccc}
\hline \multicolumn{1}{c}{ Komponen doing math } & Effect size & Interpretasi & N gain & Interpretasi \\
\hline Pemahaman & 1.16 & Tinggi & 0.44 & sedang \\
Komunikasi & 1.07 & Tinggi & 0.36 & sedang \\
Koneksi & 1.39 & Tinggi & 0.56 & sedang \\
Representasi & 1.74 & Tinggi & 0.70 & sedang \\
Penalaran & 2,52 & Tinggi & 0.57 & Sedang \\
Proving & 1,3 & Tinggi & 0.56 & sedang \\
Pemecahan masalah & \multicolumn{4}{c}{ 86\% sangat baik, 14 \% blm memadai } \\
Keseluruhan komponen & 1.42 & Tinggi & 0.36 & Sedang \\
\hline
\end{tabular}

\section{HASIL PENELITIAN}

Hasil pengolahan data yang terkumpul dalam penelitian ini, berupa data nilai pretest, postest perkomponen maupun keseluruhan kemampuan doing mathematics. Hasil perhitungan effects sizes dan N Gain kemampuan doing mathematics baik perkomponen maupun keseluruhan dapat dilihat pada Tabel 1.

Berdasarkan tabel di atas, masing-masing peningkatan nilai kemampuan doing matematics mahasiswa perkomponen maupun secara keseluruhan sangat dipengaruhi oleh pembelajaran dalam perkuliahan dan termasuk dalam kategori yang tinggi. Dengan demikian, perkuliahan kapita selekta matematika 1 , memberikan pengaruh positif terhadap peningkatan kemampuan doing mathematics mahasiswa. Sehingga penyelenggaraan perkuliahan sebaiknya ditingkatkan baik penyelenggaraannya maupun pelaksanaannya. Selanjutnya, peningkatan kemampuan doing mathematics, baik perkelompok maupun secara keseluruhan berada pada kategori sedang.

Ada beberapa temuan yang muncul selama penelitian ini berlangsung, diantaranya mahasiswa masih merasa kesulitan dalam membuktikan sifat-sifat, baik itu teorema, lemma, maupun collorary. Di awal, kemampuan bukti matematis ini dirasakan masih kurang dikuasai oleh mereka, akan tetapi seiring dengan berjalannya waktu dan materi semakin bertambah, maka pengalaman dan latihan pembuktianpun semakin bertambah.

Selain pembuktian yang dianggap sulit untuk dipahami/dikuasai selama perkuliahan berlangsung adalah kemam- puan komunikasi dan penalaran. Tapi walaupun demikian, komponen lainnya yang dipandang tidak menjadi masalah, malah nilai $\mathrm{N}$ Gainnya juga berkategori sedang semuanya. Mungkin mahasiswa perlu lebih banyak lagi latihan atau lebih banyak lagi mengerjakan bukti-bukti sifat matematika seperti teorema, lemma, collorory. Membuktikan sifat-sifat matematika seperti itu melibatkan ketiga komponen ini, yaitu bukti, komunikasi dan penalaran.

Analisis terhadap kategori gain yang diperoleh mahasiswa termasuk dalam kategori yang sedang, sangatlah mungkin, walaupun effect sizesnya berkategori tinggi. Hal ini dikarenakan, walaupun terjadi peningkatan dari pretest ke postest yang tidak terlalu besar, tetap saja ada pengaruh dari pembelajaran terhadap peningkatan kemampuan doing mathematicsnya apalagi bila simpangan bakunya kecil. Akan tetapi yang jauh lebih baik adalah selain effect sizesnya baik maka peningkatannyapun harus termasuk dalam kategori yang baik pula. Mungkin ini belum tercapai karena pembelajaran yang telah dilaksanakan masih belum optimal, dan mahasiswa pun masih belum maksimal dalam belajarnya.

Hasil analisis terhadap kemampuan pemecahan masalah matematis dapat diketahui bahwa sekitar 86\% mahasiswa memiliki kemampuan pemecahan masalah matematis yang sangat baik dan sisanya $14 \%$ berada pada level yang masih belum memadai. Analisis ini dilakukan dengan memperhatikan metode heuristic seperti yang dikemukakan oleh Poyla, bahwa pemecahan masalah itu melibatkan: memahami masalah, me- 
rencanakan pemecahan, melaksanakan pemecahan, dan meninjau kembali hasil yang diperoleh (sensible answer). Secara keseluruhan, sedikit sekali mahasiswa yang melakukan pembuktian suatu permasalahan, dan meninjau kembali hasil yang diperoleh. Dari sekitar 14\% yang kemampuan pemecahan masalah matematisnya masih belum memadai, ternyata pada umumnya mereka melakukan kekeliruan dalam menulis langkah awal penyelesaian masalah yang menyangkut cara mengemukakan pengandaian atau pemisalan yang logis. Selain itu, masih terdapat pada mahasiswa yang belum memiliki keterampilan matematis dasar yang kuat dalam penyelesaian akhirnya.

\section{PENUTUP}

Berdasarkan hasil penelitian dapat disimpulkan bahwa: (1) secara umum besar pengaruh (effect sizes) "pembelajaran" atau "perkuliahan" terhadap peningkatan kemampuan doing mathematics perkomponen maupun keseluruhan pada Mata Kuliah Kapita Selekta Matematika 1 Sekolah termasuk kategori tinggi; (2) hasil perhitungan $\mathrm{N}$ gain (peningkatan) kemampuan doing mathematics mahasiswa pada masing-masing komponen dan keseluruhan pada mata kuliah Kapita Selekta Matematika 1 termasuk kategori sedang; (3) secara umum kemampuan pemecahan masalah mahasiswa peserta perkuliahan Kapita Selekta Matematika 1 sangat baik, walaupun masih ada sebagian kecil yang belum memadai.

\section{DAFTAR PUSTAKA}

Arend, Richard. 1997. Classroom Instruction and Management. New York: Mc Graw Hill

Annette \& Sue. 1999. Assessing Problem Solving Thought Mathematics Teaching in Middle School. Mathematics Teaching in the Middle School. Volume 4 No. 5 Februari. Hal 305-311

Atweh Bill. 1998. The Construction of Social Context of Mathematics Classroom: A Sociolinguistic Analysis. Journal for Research in
Mathematics Education. 29 (1): Hal 63-82.

Baroody. A.J. 1993. Problem Solving, Reasoning, and Communicating. Macmillan Publising, New York.

Beaton, A. E. 1996. Mathematics Achievement in The Middle School Years. Boston: TIMSS International Study Center.

Bell, E.H. (1978). Teaching and Learning Secondary School Mathematics. Dubuque: WMC Brown.

Burril, J. 1997. Field Test Report: Mathematics in contex Boosts Test Scores. WCER Highlighs, Vol. 8 No. 3.

Buletin Educational Innovation and Information Nomor 97-105: IBE

Cai ,J \& Patricia. 2000. Fostering Mathematical Thinking through Multiple Solutions. Mathematics Teaching in the Middle School. Volume 5 No 8 April 2000.www.nctm.org/ mtms/2000/04/index.htm, diakses 8 April 2001.

Cobb, Paul. 1997. Instructional Design and Reforma: A Plea for Developmental Research in Contex. . In Beishuizein, Gravemeijer \& van Leishout (Eds.). The Role Of Contexts and Models in The Development of Mathematical Strategies and Procedures. CD- $\beta$ Series On Research And Mathematics Education. Freudenthal Institute Utrecht Belanda.

Cobb, Yackel \& Wood. 1992. A Contructivist alternative to the representational view of Mind in Mathematics Education. Journal for Research in Mathematics Education. 23: Hal 2-33.

De Lange, J. 1987. Mathematics insight and meaning. OW\&OC. Utrecht: University Press.

De Lange, J. 1995. Assessment: no change without problems, In Romberg, TA. (Ed). Reform in School Mathematics and authentic assessment. New York: Sunny Press.

Ellis, 2013, The Essential Guide to Effect Sizes, Mexico City: Cambridge University Press. 
2011, Hypothesis Testing, Wiki, Series, Memphis: Books LLC.

Hake, RR 1998, Analyzing Change/Gain score, Department of Physics, Indiana University.

IBE. 2000. Improving students achievement in Mathematics. Educational Practice Series-4. IBE.UNESCO.

Lappan.G. 2002. Connected Mathematics Project: Research and Evaluation Summary.

Meel, David E. (2003). Models and Theories of Mathematical Understanding: Comparing Pirie and Kieren's Model of the Growth of Mathematical Understanding and APOS Theory. CBMS Issues in Mathematics Education, 12, 132-181.

National Council of Teachers of Mathematics. 1989. Curriculum and Evaluation Standards for School Mathematics. Reston, Virginia: NCTM.

National Council of Teachers of Mathematics. 1990. "Contructivist Views on The Teaching ang Learning of Mathematics". Journal for Research in Mathematics Education. Reston, Virginia:NCTM.

National Council of Teachers of Mathematics. 2000a. Principles and Standards for School Mathematics. NCTM: Reston VA.

National Council of Teachers of Mathematics. 2000b. Learning Mathematics For A New Century. 2000Yearbook NCTM: Reston VA.

National Science Foundation. 1998. Mathematics in Context: Teachers Resource and Implementation Guide. Chicago: Encyclopedia Britanica Ed. Co.

National Science Foundation. 2000. The Core-Plus Mathematics Project (CPMP), (Online), www.mich. edu/cpmp/front.html, Diakses 21 Agustus 2000).

Orton, Anthony. 1992. Learning Mathematics: Issues, Theory and Classroom Practice. Cassell Education Series. London.
Palincsar, A.S. (1986). Reciprocal teaching. In Teaching reading as thinking. Oak

Brook, IL: North Central Regional Educational Laboratory.

Pugalee, David. 2001. Using Communication to Develop Students' Mathematical Literacy. Mathematics Teaching in The Middle School Vol 6 No 5 Januari. Hlm: 296-299

Schifter, D. and Fosnot, C.T. (1993). Reconstruction Mathematics Education. Teacher's College, Columbia University.

Schoenfeld, A.H. 1991. On Mathematics as Sense Making: An Informal Attach on the Unfornute Divorce of Formal and Informal Mathematics. In J.F Voss, D.N. Perkins \& J.W Segal (Eds.) Informal Reasoning and Education. 311-344. Hillsdale NJ: Erlbaum.

Seegers,G \& Gravemeijer, K. 1997. Implementation and Effect Of Realistic Curricula. In Beishuizein, Gravemeijer \& van Leishout (Eds.). The Role Of Contexts and Models in The Development of Mathematical Strategies and Procedures. CD- $\beta$ Series On Research And Mathematics Education. Freudenthal Institute Utrecht Belanda.

Simon. M.A. 1995. Reconstructing mathematics pedagogy from a constructivist perspective. Journal for Research in Mathematics Education. 26, 115-145.

Slavin, Robert. 1994. Educational Psychology: Theories and Practice. Fourth Edition. Massachusetts: Allyn and Bacon Publisher.

Slettenhaar, 2000, Adapting Realistic Mathematics Education in The Indonesia Context. Dalam Majalah Ilmiah Himpunan Matematika Indonesia. (Prosiding Konferensi Nasional Matematika X, ITB, 17-24 Juli 2000.

Souviney, R.J. 1994. Learning to Teach Mathematics. New York: Addison Wesley. 
Tom Gorris. 1998. Reforms in secondary math education in the Netherland. www.fiuu.nl/en/indexpublicaties.

UNESCO. 1998. Education For the Twenty-first century: issues and prospects. Unesco Publishing

Verschafel, L.\&De Corte, E. 1997. Teaching Realistics Mathematical Modeling in the Elementary School: A Teaching Experiment with Fifth
Graders. Journal for Research in Mathematics Volume 28 No 5, November: 577-601.

Zawojewski, J.S, Robinson, M, \& Hoover, M. 1999. Reflections on Developing Mathematics and the Connected Mathematics Project. Journal for Mathematics Teaching in the Middle School. 4: 324-330. 